\title{
Erratum
}

\section{Dynamics of the Open BCS Model}

\section{Emmanuel Buffet ${ }^{1}$ and Philippe A. Martin ${ }^{1}$}

Received November 31978

The attention of the reader is drawn to several misprints which may obscure the understanding of our paper ${ }^{(1)}$ :

Page 599, line 15 should read: "We assume that the decay in time of $C_{1}(t)$ and $C_{2}(t)$ is $O\left(1 / t^{1+\eta}\right), \eta>0$, for $t \rightarrow \infty$."

Page 599, the argument of the first $C_{2}$ function occurring on the righthand side of formula (47) should be $-t$ (and not $+t$ ).

Page 611, Figs. $2 \mathrm{a}$ and $2 \mathrm{~b}$ should be interchanged.

Page 611, the last line of Section 4.2 should read

$$
\hat{C} \equiv 1, \quad \epsilon=1, \quad \mu=4 \quad \text { (which gives } \beta_{C}=0.549 \text { ) }
$$

\section{REFERENCE}

1. E. Buffet and Ph. A. Martin, J. Stat. Phys. 18:585 (1978).

\footnotetext{
${ }^{1}$ Laboratoire de Physique Théorique, Ecole Polytechnique Fédérale de Lausanne,
} Lausanne, Switzerland. 